\title{
Wind Turbine Blade Nondestructive Testing with a Transportable Radiography System
}

\author{
J. G. Fantidis, ${ }^{1}$ C. Potolias, ${ }^{2}$ and D. V. Bandekas ${ }^{2}$ \\ ${ }^{1}$ Laboratory of Nuclear Technology, Department of Electrical and Computer Engineering, School of Engineering, \\ Democritus University of Thrace, Kimmeria Campus, Xanthi 67100, Greece \\ ${ }^{2}$ Department of Electrical Engineering, Kavala Institute of Technology, Agios Loukas, Kavala 65404, Greece
}

Correspondence should be addressed to J. G. Fantidis, fantidis@yahoo.gr

Received 17 November 2010; Revised 27 January 2011; Accepted 28 February 2011

Academic Editor: Luigi Petrizzi

Copyright () 2011 J. G. Fantidis et al. This is an open access article distributed under the Creative Commons Attribution License, which permits unrestricted use, distribution, and reproduction in any medium, provided the original work is properly cited.

\begin{abstract}
Wind turbines are becoming widely used as they are an environmentally friendly way for energy production without emissions; however, they are exposed to a corrosive environment. In addition, as wind turbines typically are the tallest structures in the surrounding area of a wind farm, it is expected that they will attract direct lightning strikes several times during their operating life. The purpose of this paper is to show that the radiography with a transportable unit is a solution to find defects in the wind turbine blade and reduce the cost of inspection. A transportable neutron radiography system, incorporating an Sb-Be source, has been simulated using the MCNPX code. The simulated system has a wide range of radiography parameters.
\end{abstract}

\section{Introduction}

At the end of 2008, worldwide nameplate capacity of windpowered generators was approximately $121 \mathrm{GW}$ [1]. Today the largest wind turbines generate $6 \mathrm{MW}$ and involve glass fibre reinforced plastics (GRP) blades up to $126 \mathrm{~m}$ in length. These blades will be subject to enormous stresses, especially in storm conditions. Damages to the wind turbine blades are relatively serious since the cost for replacements is really high and time-consuming repair service is needed. It is considered as an obstruction factor to the expansion of the wind turbine installation [2]. Wind turbine blades must be inspected during and after manufacture, and often during their service life, to ensure that their condition is suitable for their purpose.

Radiography is a powerful nondestructive method. Gamma ray radiography technique is frequently used, either on its own or as complementary to neutron radiography (NR), for the analysis of objects. Both methods can be used either in $2 \mathrm{D}$ mode to take radiographs or with a tomography setup in 3D mode. Radiography allows the detection of internal flaws and defects such as cracks, corrosion, inclusions, and thickness variations; consequently, it is a technique of growing importance to science and industry in order to determine structural defects $[3,4]$.

The most common gamma rays sources, which are commonly used for radiography purposes, such as ${ }^{137} \mathrm{Cs}$ and ${ }^{60} \mathrm{Co}$, are made artificially. The gamma rays are emitted as line spectra of discrete energies and different relative intensities, which are the characteristic of the particular source. In this work, a transportable unit for radiography, based on the use of $\mathrm{Sb}-\mathrm{Be}$ isotopic source incorporated within it, has been simulated using the MCNPX Monte Carlo code [5]. The aim is to optimize the design of the unit with reference to its collimator and shielding, rendering it suitable for quality nondestructive testing, while ensuring appropriate radiation protection and safety standards for the personnel in the neighborhood of the system.

\section{Materials and Methods}

2.1. The $S b-B e$ Source. Fantidis et al. have showed that it is possible to design a transportable unit which incorporates an $\mathrm{Sb}$-Be source, which is capable to provide a wide range of values for the parameters characterising the neutron and gamma radiographies. This means that the unit is capable 
to produce radiographies of variable quality [6]. For gamma radiography, the unit uses only the ${ }^{124} \mathrm{Sb}$ source. The ${ }^{124} \mathrm{Sb}$ source $\left(t_{1 / 2}=60.2\right.$ days $)$ emits a large number of photons with energy higher than common isotopic source like ${ }^{137} \mathrm{Cs}$ and ${ }^{60} \mathrm{Co}$. Just like other gamma sources it is portable; it can be operated without the electricity or cooling water. The gamma ray spectrum from the decay of ${ }^{124} \mathrm{Sb}$ has been experimentally derived by Patil et al. and has been used for the intentions of this paper [7]. According to this spectrum, photons with energy $603 \mathrm{keV}$ and $1691 \mathrm{keV}$ have the highest intensity. The $1.691 \mathrm{MeV}$ gamma-line of ${ }^{124} \mathrm{Sb}$ can be suitable for gamma radiography for bulky dense objects, for example, the wind turbine blades. Gamma radiation is emitted continuously and cannot be switched off, which means that for reasons of safety the ${ }^{124} \mathrm{Sb}$ source must be kept in a special container shielded usually with lead $(\mathrm{Pb})$. The design offers the possibility to lift the ${ }^{124} \mathrm{Sb}$ source and the lid $(L)$ which covers it, by a simple remote control mechanism (Figure 1).

The Sb-Be neutron source effectively comprises two parts: the ${ }^{124} \mathrm{Sb}$ isotope and a Be target. Neutrons are formed from the interaction of the photons emitted from ${ }^{124} \mathrm{Sb}$ with the Be by means of the photoneutron production reaction ${ }^{9} \mathrm{Be}(\gamma, n)^{8} \mathrm{Be}$. The threshold energy of the reaction is approximately $1.667 \mathrm{MeV}$. The source emits neutrons with a soft spectrum having an average energy at $24 \mathrm{keV}$ and a small fraction of fast neutrons. Bücherl et al. have simulated, using the MCNPX code, the neutron spectrum with an excellent agreement to experimental results $[8,9]$. The thickness of the Be target for maximum neutron yield was calculated by Monte Carlo simulations using [10]

$$
w(E)=\frac{\sigma_{(\gamma n)}(E)}{\sigma_{\text {tot }}(E)}\left(1-\exp \left[\sigma_{\text {tot }}(E) n \Delta\right]\right),
$$

where $w(E)$ is the neutron yield per gamma quanta emitted in the ${ }^{124} \mathrm{Sb}$ source, $\sigma_{y n}$ is the photoneutron production cross section, $\sigma_{\text {tot }}$ is the total photon scattering and absorption cross section, $n$ and $\Delta$ are the density and thickness of the Be target [10]. The number of produced neutrons equals

$$
N_{n}=\int_{E_{0}}^{+\infty} \frac{d N}{d E} w(E) d E .
$$

In accordance with (1), the neutron yield is proportional to the thickness of the Be. Nevertheless, an augment of the thickness would be accompanied by an augment of the total dimensions and weight of the system. Hence, the choice of the $\mathrm{Be}$ is a compromise between beam intensity and transportability for insitu testing. The Sb-Be source has a low cost in setup and maintenance in comparison with low power (research) reactors or accelerator-driven neutron sources. In addition, the $\mathrm{Sb}-\mathrm{Be}$ source has the advantage to offer an on/off switching capability (compared with radioisotopic sources, e.g., ${ }^{252} \mathrm{Cf}$ ) since the subtraction of the Be target ceases the production of the neutrons. This makes the transportation of the source easier since only shielding for the gamma emitted by ${ }^{124} \mathrm{Sb}$ would be required. The source has one main disadvantage when used for NR: the high specific gamma activity of ${ }^{124} \mathrm{Sb}$. This can be overcame using

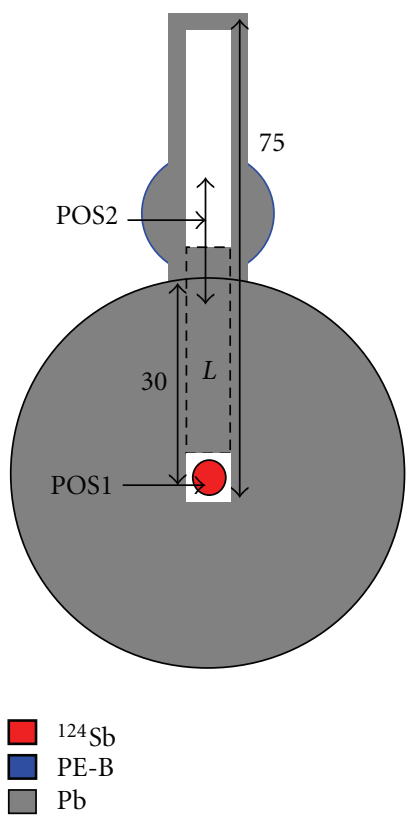

FIGURE 1: Side view of the mobile Sb-Be source-not in scale (all dimensions in $\mathrm{cm}$ ).

gamma insensitive neutron detection plates $[11,12]$ and with image filtering in digital NR [9].

2.2. Simulation of the Radiography Unit. The radiography layout consists of two main units: the attachable transport and shielding container for the ${ }^{124} \mathrm{Sb}$ source and the radiography source container. Both parts are designed in the form of a sphere with a radius of 30 and $13 \mathrm{~cm}$, respectively. Side view through the centre of the unit is shown in Figure 1. The ${ }^{124} \mathrm{Sb}$ part of the source has been simulated as a sphere with $1 \mathrm{~cm}$ radius and is symmetrically placed at the centre of the bigger sphere (POS1) which is the source container when not used for radiography purposes. This sphere is made of $\mathrm{Pb}$ providing the necessary shielding against the photons from the ${ }^{124} \mathrm{Sb}$ source which is considered yielding a $4.1 \times 10^{13} \mathrm{~Bq}$. When the unit is in use, the ${ }^{124} \mathrm{Sb}$ source is placed in position 2 (POS2). During use of the unit, the conic shape shielding sectors $\mathrm{S} 1$ and $\mathrm{S} 2$ can be removed to allow placing collimators in order to provide a path for the photons and neutrons from the source towards the objects being imaged (Figure 2). The second sphere was a combination of two materials: an $11 \mathrm{~cm}$ thick layer of $\mathrm{Pb}$ in order to stop the gamma rays and a $1 \mathrm{~cm}$ layer of borated polyethylene (PE-B) with the purpose to eliminate any thermal neutrons diffusing out of the unit.

Figure 3 shows the unit with a neutron and a gamma collimator in positions S2 and S1, respectively. The use of the ${ }^{124} \mathrm{Sb}$ source for gamma radiography requires a simple collimator which is shown in position S1. A divergent collimator made of $7 \mathrm{~cm}$ thick $\mathrm{Pb}$ walls was used. The first $11 \mathrm{~cm}$ of the collimator wall were provided by the $\mathrm{Pb}$ spherical unit itself while the total length could be extended in proportion to the application. A good quality image is required to be sharp, and the geometric unsharpness, $U_{g}$, 


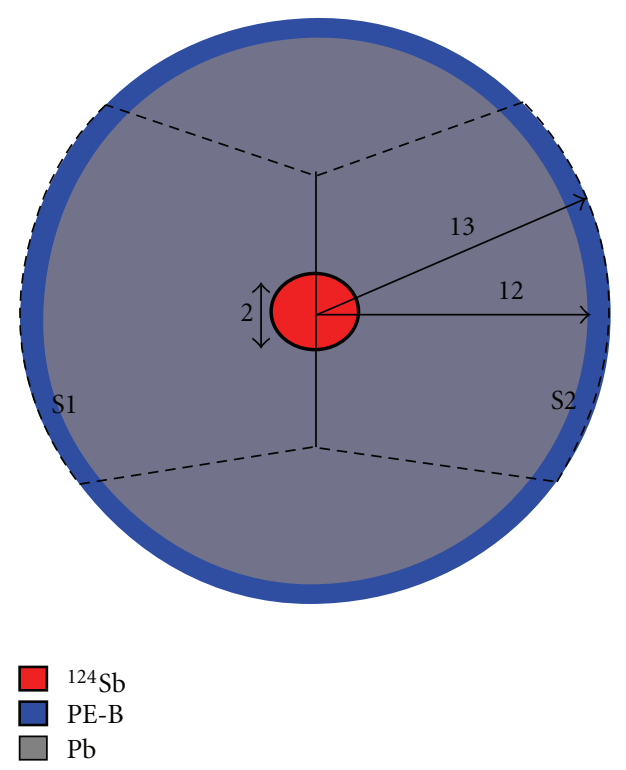

FIGURE 2: Side view of the transportable unit when the Sb-Be source is situated in the POS2-not in scale (all dimensions in $\mathrm{cm}$ ).

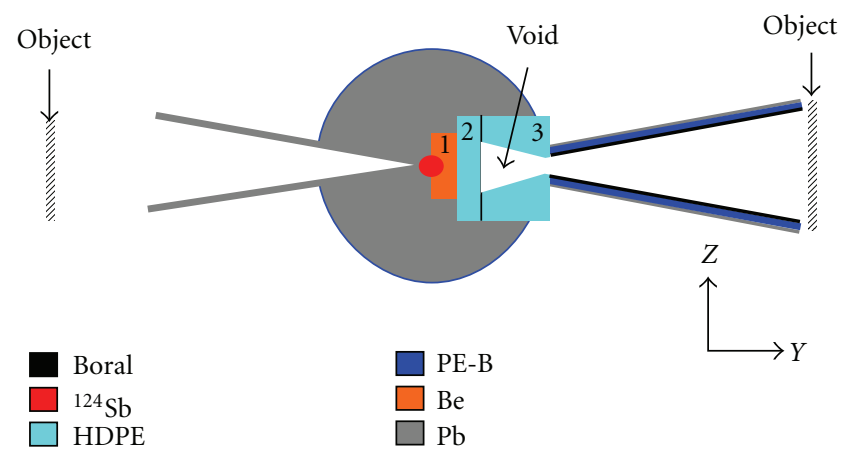

Figure 3: Geometric configuration of the suggested layout with the two different types of collimators-not in scale.

for significant object thicknesses can be expressed by the formula:

$$
U_{g}=f \frac{b}{a}
$$

where $f$ is the source focal-spot size, $a$ is the distance from the source to front surface of the object, and $b$ is the thickness of the object. Codes and standards used in industrial radiography require that the $U_{g}$ is as small as possible. In general, the allowable amount is $1 / 100$ of the material thickness up to a maximum of $0.1 \mathrm{~cm} \mathrm{[13].}$

The collimator ratio $(L / D)$ determines the quality of the NR imaging for a given design of the collimator, which is governed by:

$$
\begin{gathered}
\phi_{i}=\frac{\phi_{\alpha}}{16\left(L_{S} / D\right)^{2}}, \\
U_{g}=L_{f} \frac{D}{L_{s}},
\end{gathered}
$$

where $L_{f}$ is the image surface to object distance, $L_{s}$ is the source to object distance, $D$ is the inlet aperture diameter, $\phi_{i}$ is the neutron flux at the image plane, $\phi_{\alpha}$ is the neutron flux at the aperture, and $U_{g}$ is the geometric unsharpness. The beam divergence, a significant measure of the usefulness of the beam near its periphery, is described by its half-angle $(\theta)$ given by [14]

$$
\theta=\tan ^{-1}\left(\frac{I}{2 L}\right)
$$

where $I$ and $L$ are the maximum dimension of the image plane and the length of the collimator. The imaging quality of a system would be further characterized by the Thermal Neutron Content (TNC), which describes the number of thermal neutrons within the neutron beam

$$
\mathrm{TNC}=\frac{\text { thermal neutron flux }}{\text { total neutron flux }}
$$

and the relative intensities of the neutron $(n)$ and the photon $(\gamma)$ components of the beam $(n / \gamma)$. Hawkesworth [15] has shown that the least recommended value is about $500 \mathrm{n} \mathrm{cm}^{-2} \mathrm{mSv}^{-1}$. However, while digital radiography would allow fast image-processing (spatial, average, median, and sharpening filters) [9] and with the development of new gamma insensitive neutron detection plates, a ratio less than this can also be justified. The use of the system for NR demands a dedicated collimator which is shown in position S2 (Figure 3). Next to the ${ }^{124} \mathrm{Sb}$ source, there is the Be target (1) with dimensions $2.3 \mathrm{~cm} \times 5 \mathrm{~cm} \times 5 \mathrm{~cm}$ (in $x, y, z$ axis, resp.). According to (1), a $4.1 \times 10^{13} \mathrm{~Bq}{ }^{124} \mathrm{Sb}$ source is considered yielding $4.1 \times 10^{9} \mathrm{n} / \mathrm{s}$. The photoneutrons formed, with an average energy of about $24 \mathrm{keV}$, are thermalised using $1 \mathrm{~cm}$ thick high density polyethylene (HDPE), providing a maximum thermal neutron flux at the collimator inlet aperture.

The collimator being used for NR comprises two parts. The first is a rectangular HDPE (3) with dimensions $5 \mathrm{~cm} \times 11 \mathrm{~cm} \times 5 \mathrm{~cm}$ (in $x, y, z$ axis, resp.). Inside of them, there is a void conic collimator with length $11 \mathrm{~cm}$, radii $3 \mathrm{~cm}$, and $0.5 \mathrm{~cm}$, with the larger radius near to the source. Calculations with MCNPX were carried out in order to determine the void collimator length, which would give the maximum thermal neutron flux at the object. The length was determined to be $11 \mathrm{~cm}$.

Next to the rectangular HDPE and the void collimator there is a divergent collimator, determining to a great extent the quality of the image for a given source type. The material used in the design of the collimator should prevent stray and scattered neutrons from reaching the object through absorbing them, hence improving the unsharpness of the obtained image. In this respect, the inner lining of the collimator is particularly important and it should be made of a neutron-absorbing material [14]. The lining is composed of a $1 \mathrm{~cm}$ layer of boron. The borated polyethylene (PE-B) with $3 \mathrm{~cm}$ depth was chosen among the available materials as a filling material in the collimator, since it provides a good shielding against stray neutrons. $1 \mathrm{~cm}$ thick Bismuth (Bi) layer was chosen as the collimator casing. 
The most commonly used types of composite material in the wind turbine industry are GRP. GRP dominates the market because it provides the necessary properties at a low cost. Glass fibre is manufactured from glass manufacturing materials such as silicate, colemanit, aluminum oxide, and soda. Glass fibre is the most commonly known and used one among fibre contributed composites. On wind turbine blades E-Glass type is used. The chemical composition of Eglass is $\mathrm{SiO}_{2} 54.3 \%, \mathrm{Al}_{2} \mathrm{O}_{3}$ and $\mathrm{Fe}_{2} \mathrm{O}_{3} 15.2 \%, \mathrm{CaO} 17.3 \%$, $\mathrm{Na}_{2} \mathrm{O} / \mathrm{K}_{2} \mathrm{O} 0.6 \%$, and $\mathrm{B}_{2} \mathrm{O}_{3} 8 \%$ to $10 \%$ [16-18]. Properties that have made E-glass so popular in fibreglass include low cost, high production rates, high strength, high stiffness, relatively low density, non-flammable, resistant to heat, good chemical resistance, relatively insensitive to moisture, able to maintain strength properties over a wide range of conditions, and good electrical insulation. The advantageous properties of E-glass generally outweigh the disadvantages which include low modulus, self abrasiveness (if not treated appropriately), relatively low fatigue resistance, and higher density compared to carbon fibres and organic fibres [19].

\section{Results and Discussion}

Wind Turbines will be installed on a tower which is between $50-135 \mathrm{~m}$ tall, have diameters (blade span) from 40 to $126 \mathrm{~m}$ and are rated between $500 \mathrm{~kW}-6 \mathrm{MW}[20,21]$. As a consequence, the minimum distance from blade to ground is about $30 \mathrm{~m}$. Turbine towers are constructed from rolled steel plate and are normally about 4 to $5 \mathrm{~m}$ diameter at the base and about 2 to $3 \mathrm{~m}$ diameter at the top. A portable NDT scanning system is required to detected internal defects in the wind turbine.

3.1. Dose Results/Requirements. The system was designed under the constraint that the Dose Equivalent Rate (DER) would not overcome the annual occupational dose limit of $0.5 \mathrm{~Sv}$ ( or $25 \mu \mathrm{Sv} \cdot \mathrm{hr}^{-1}$ ). When the ${ }^{124} \mathrm{Sb}$ source is situated in the POS1, the total dose rate, due to the photons, was calculated with the MCNPX Monte Carlo code, using the F2, Fm 2 tallies and the DE, DF cards. The F tallies describe the flux within a cell, while the D cards convert the absorbed dose to equivalent dose. Calculations were performed with NPS $=2 \times 10^{6}$ histories yielding an accuracy $<1 \%$. The resulting total DER is $21.2 \mu \mathrm{Sv} \cdot \mathrm{hr}^{-1}$. When the ${ }^{124} \mathrm{Sb}$ source is in POS2, the total DER is about $18.7 \mu \mathrm{Sv} \cdot \mathrm{hr}^{-1}$ and comprises the photon and neutron components with values of $18.7 \mu \mathrm{Sv} \cdot \mathrm{hr}^{-1}$ and $0.02 \mu \mathrm{Sv} \cdot \mathrm{hr}^{-1}$, respectively. The induced photons from the interaction of the neutrons and the PE moderator material result in a dose which is about three orders of magnitude less than the dose from the ${ }^{124} \mathrm{Sb}$ photons.

Figure 4 shows the resulting gamma dose rates at the surface of the system, and at a distance of $30 \mathrm{~m}$, respectively, for different thicknesses of the $\mathrm{Pb}$ shielding surrounding the ${ }^{124} \mathrm{Sb}$ source. Hence, the dimensions of the proposed unit, satisfying the occupational dose limit, constraint are approximately $60 \mathrm{~cm} \times 60 \mathrm{~cm} \times 105 \mathrm{~cm}(W \times L \times H)$, and the overall weight is about $1600 \mathrm{~kg}$. Is much easier, safer

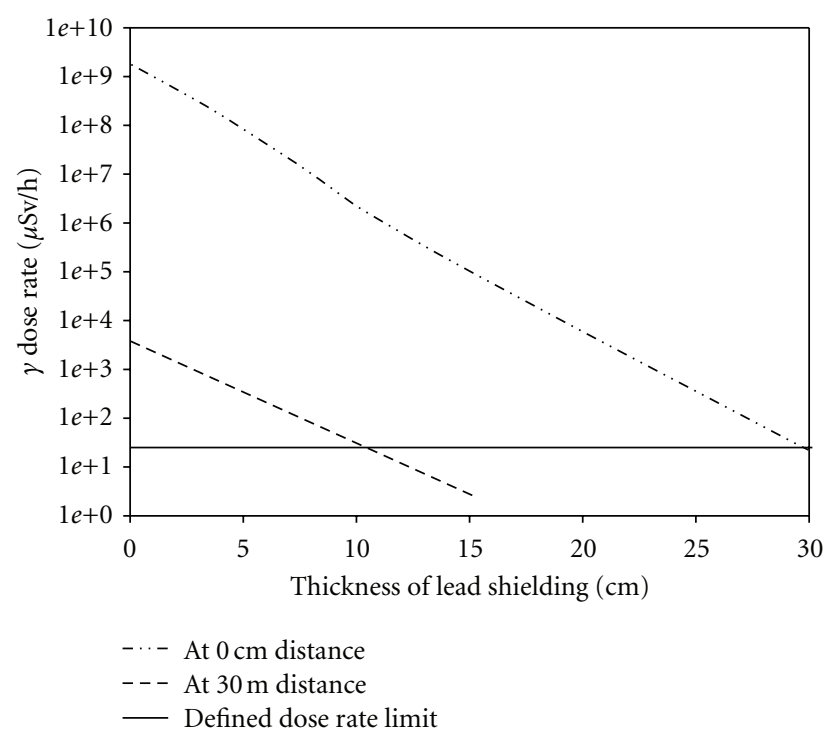

Figure 4: Calculated gamma dose rates for different distances from the surface of the unit as a function of the thickness of lead.

TABLe 1: The calculated parameters for gamma ray radiography system, with $20 \mathrm{~cm}$ thickness of the object and $1 \mathrm{~cm}$ source-focal spot size (all values for $1.691 \mathrm{MeV}$ photons).

\begin{tabular}{ccccccc}
\hline $\begin{array}{c}L \\
(\mathrm{~cm})(\mathrm{cm})\end{array}$ & $\begin{array}{c}\text { Spot size } \\
(\mathrm{cm})\end{array}$ & $\begin{array}{c}\theta \\
\left({ }^{\circ}\right)\end{array}$ & $\begin{array}{c}U_{g} \\
(\mathrm{~cm})\end{array}$ & $\begin{array}{c}f_{\text {gamma }}^{*} \\
\left(\mathrm{~g} \mathrm{~cm}^{-2} \mathrm{~s}^{-1}\right)\end{array}$ & $\begin{array}{c}\text { Uncollided } \\
\text { gamma* } \\
(\%)\end{array}$ \\
\hline 75 & 200 & 30 & 4.29 & $1.00 E-1$ & $1.07 E+7$ & 99.24 \\
80 & 220 & 35 & 4.54 & $9.09 E-2$ & $9.12 E+6$ & 99.24 \\
85 & 240 & 40 & 4.76 & $8.33 E-2$ & $7.79 E+6$ & 99.25 \\
90 & 260 & 45 & 4.94 & $7.69 E-2$ & $6.75 E+6$ & 99.25 \\
95 & 280 & 50 & 5.1 & $7.14 E-2$ & $5.90 E+6$ & 99.22 \\
100 & 300 & 60 & 5.71 & $6.67 E-2$ & $5.34 E+6$ & 99.27 \\
\hline
\end{tabular}

* $1.691 \mathrm{MeV}$.

and inexpensive this unit with a combination of a simple detectors array to lift in the same height with turbine blade comparatively to move the blades to an inspection laboratory in the ground.

3.2. Gamma Radiography Results. The proposed system was simulated, with the MCNPX code, for gamma radiography, making use of the fact that the ${ }^{124} \mathrm{Sb}$ is a strong photon emitter. Photon fluxes were calculated using the F2 tally which gives the required photon flux averaged over a surface in photons $\mathrm{cm}^{-2}$ per starting photon. Calculations were carried out with NPS $=7 \times 10^{7}$ histories yielding an accuracy $<1 \%$ (Table 1 ). The system has been considered with a variable collimator length $(L=75-100 \mathrm{~cm})$, source to object distance $(a=200-300 \mathrm{~cm})$, and divergence angle $\left(\theta=4.29-5.71^{\circ}\right)$. With the purpose to determine the $U_{g}$, the thickness of the object was assumed to be $20 \mathrm{~cm}$. A source focal-spot size $(f)$ of $1 \mathrm{~cm}$ was considered in order to keep $U_{g}$ below the recommended value of $0.1 \mathrm{~cm}$. The collimation 
TABLE 2: The NR calculated parameters using the proposal system.

\begin{tabular}{|c|c|c|c|c|c|c|c|c|}
\hline$L(\mathrm{~cm})$ & $L / D$ & $D_{0}(\mathrm{~cm})$ & $\theta\left(^{\circ}\right)$ & $U_{g}(\mathrm{~cm})$ & $f_{\text {th }}$ & TNC (\%) & $n / \gamma\left(\mathrm{ncm}^{-2} \mathrm{mSv}^{-1}\right)$ & Time (min) \\
\hline 25 & 25 & 12 & 13.49 & $2.00 E-2$ & $5.16 E+4$ & 14.88 & $6.31 E+3$ & 0.32 \\
\hline 30 & 30 & 14 & 13.13 & $1.67 E-2$ & $2.71 E+4$ & 13.69 & $5.05 E+3$ & 0.61 \\
\hline 40 & 40 & 16 & 11.31 & $1.25 E-2$ & $1.08 E+4$ & 12.50 & $2.58 E+3$ & 1.55 \\
\hline 50 & 50 & 18 & 10.2 & $1.00 E-2$ & $5.96 E+3$ & 12.37 & $2.26 E+3$ & 2.80 \\
\hline 60 & 60 & 20 & 9.46 & $8.33 E-3$ & $3.69 E+3$ & 12.02 & $1.56 E+3$ & 4.52 \\
\hline 70 & 70 & 22 & 8.93 & $7.14 E-3$ & $2.43 E+3$ & 11.69 & $1.48 E+3$ & 6.87 \\
\hline
\end{tabular}

system has been designed to obtain a spot of $30-60 \mathrm{~cm}$ in diameter of the photon beam at the object position.

The variation of the photon flux at the field of view at the object position was less than $1 \%$. The photon neutron flux varies from $5.3 \times 10^{6}$ up to $1.1 \times 10^{7} \mathrm{p} \mathrm{cm}^{-2} \mathrm{~s}^{-1}$ for a maximum activity of the ${ }^{124} \mathrm{Sb}\left(4.1 \times 10^{13} \mathrm{~Bq}\right)$. In keeping with Table 1, the uncollided photon flux which characterizes the beam quality has excellent values from 99.22 up to $99.27 \%$.

3.3. Neutron Radiography Results. In terms of the thermal NR $\left(f_{\text {th }}\right)$ the proposed unit has collimator with a variable collimator length $(L=25-70 \mathrm{~cm})$, variable diameter of its aperture next to the image plane $\left(D_{0}=12-22 \mathrm{~cm}\right)$, changeable divergence angle of the beam $\left(\theta=8.93-13.49^{\circ}\right)$, and an inlet aperture $(D)$ of the collimator of $1 \mathrm{~cm}$. The distance between the object and the imaging detector $\left(L_{f}\right)$ was considered at $0.5 \mathrm{~cm} \mathrm{[15].} \mathrm{The} \mathrm{variation} \mathrm{of} \mathrm{the} \mathrm{thermal}$ neutron flux at the field of view at the object position was less than $3 \%$. The $f_{\text {th }}$ TNC and $(n / \gamma)$ parameters calculated are shown in Table 2 for different collimator parameters. The neutron flux was calculated with the aid of the MCNPX code using the F2 tally. Calculations were executed with NPS $=10^{7}$ histories for neutrons yielding an accuracy $<1.5 \%$. An energy boundary of $0.01-0.3 \mathrm{eV}$ was used to score the thermal neutron flux. The gamma dose in the ratio $n / \gamma$ was calculated with F2, Fm2 tallies and the DE, DF cards. Calculations were performed for NPS $=6 \times 10^{8}$ yielding an accuracy in the calculations of $<2 \%$.

According to Table 1 , the $n / \gamma$ parameter remains in all circumstances above the recommended limit. The $f_{\text {th }}$ varies from $2.4 \times 10^{3}$ up to $5.2 \times 10^{4} \mathrm{n} \mathrm{cm}^{-2} \mathrm{~s}^{-1}$ for a maximum neutron yield. The TNC varies from $11.7-14.9 \%$ and the $n / \gamma$ range from $1.5 \times 10^{3}$ up to $6.3 \times 10^{3} \mathrm{n} \mathrm{cm}^{-2} \mathrm{mSv}^{-1}$. Good-quality thermal neutron images require exposures of the order of $10^{6} \mathrm{n} \mathrm{cm}^{-2}$ [22], with the exposure time being proportional to the thermal neutron flux. The exposure time varies between 3.2 and $68.7 \mathrm{~min}$ for $L / D 25$ and 70 , respectively.

Figure 5 shows two characteristics radiographic images of a typical turbine blade using the gamma rays (a) and neutrons (b) from the proposed unit. These figures were plotted from the MCNPX Visual Editor. In the blade, there are two defects, a small cylindrical void (1) with dimensions of $0.05 \mathrm{~cm}$ radius and $1.5 \mathrm{~cm}$ height and a small sphere from water (2) with radius $0.2 \mathrm{~cm}$. The void is distinguishable in both figures but the water sphere is distinct only in

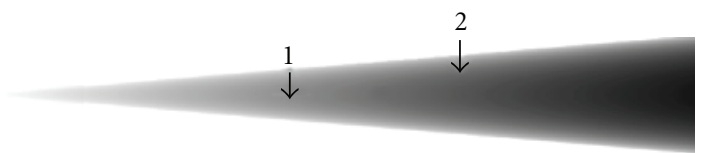

(a)

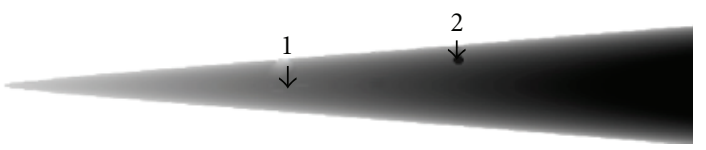

(b)

FIGURE 5: Gamma ray and neutron radiography of a wind turbine blade.

the second figure; this is due to the much higher linear attenuation coefficient of hydrogen for thermal neutrons compared to gamma rays. From a number of radiography images obtained at different rotation angles of the sample, a $3 \mathrm{D}$ representation of the object can be computed. The method is known as neutron computed tomography [23, 24]. Computed tomography with its extremely high contrast resolution (ability to measure small density differences) and high spatial resolution (ability to resolve fine structural details) makes attractive for critical inspection requirements of turbine blades, where failure would result in extremely high costs and possibly lives.

\section{Conclusions}

A transportable system using an $\mathrm{Sb}-\mathrm{Be}$ source has been simulated to provide access to wind turbine blades, with gamma and neutron radiography purposes, using the MCNPX Monte Carlo code. The Sb-Be source has some considerable advantages like low cost and easy transportation and on/off switching of the neutron source. Appropriate collimators have been simulated for the two radiographies options. Radiography with photons and neutrons made possible in extracting internal features of blade including inaccessible areas nondestructively, which is not possible through conventional method.

\section{References}

[1] World Wind Energy Association, "World Wind Energy Report 2008," February 2009, Retrieved March 2009.

[2] I. Cotton, B. McNiff, T. Soerenson et al., "Lightning protection for wind turbines," in Proceedings of the 25th International 
Conference on Lightning Protection (ICLP' 02 ), p. 848, Rhodes, Greece, 2000.

[3] W. J. Lewis, L. G. I. Bennett, T. R. Chalovick, and O. Francescone, "Neutron radiography of aircraft composite flight control surfaces," in Proceedings of the 15th World Conference on Nondestructive Testing, Roma, Italy, October 2000.

[4] M. A. S. Pereira, F. Pugliesi, and R. Pugliesi, "Neutron induced radiography. A technique to inspect the internal structure of thin samples," Brazilian Journal of Physics, vol. 38, no. 3, pp. 346-349, 2008.

[5] D. B. Pelowitz, "MCNPXTM User's Manual Version 2.5.0," 2005.

[6] J. G. Fantidis, G. E. Nicolaou, and N. F. Tsagas, "A transportable neutron radiography system based on a SbBe neutron source," Nuclear Instruments and Methods in Physics Research A, vol. 606, no. 3, pp. 806-810, 2009.

[7] A. Patil, D. Santhosh, K. Vijay Sai, M. Sainath, and K. Venkataramaniah, "Precision measurements in Te following the decay of Sb," Applied Radiation and Isotopes, vol. 64, no. 6, pp. 693-699, 2006.

[8] T. Bücherl, N. Kardjilov, C. L. Von Gostomski, E. Calzada, and A. M. ELGhobary, "A mobile neutron source based on the SbBe reaction," Applied Radiation and Isotopes, vol. 61, no. 4, pp. 659-662, 2004.

[9] T. Bücherl, N. Kardjilov, CH. L. Von Gostomski, and E. Calzada, "Performance studies of a mobile neutron source based on the SbBe reaction," IEEE Transactions on Nuclear Science, vol. 52, no. 1, pp. 342-345, 2005.

[10] D. A. Gryaznykh, V. A. Lykov, and V. V. Plokhoi, "Estimations of neutron yield from beryllium target irradiated by SPring- 8 hard synchrotron radiation," Nuclear Instruments and Methods in Physics Research A, vol. 448, no. 1, pp. 106-108, 2000.

[11] S. Masalovich, A. Ioffe, M. Schlapp, H. Von Seggern, E. Küssel, and TH. Brückel, "Optimization of a neutron image plate detector with low $\gamma$-sensitivity," Nuclear Instruments and Methods in Physics Research A, vol. 539, no. 1-2, pp. 236-249, 2005.

[12] G. A. Appleby, C. M. Bartle, G. V. M. Williams, and A. Edgar, "Lithium borate glass ceramics as thermal neutron imaging plates," Current Applied Physics, vol. 6, no. 3, pp. 389-392, 2006.

[13] R. A. Quinn and C. C. Sigl, Radiography in Modern Industry, Eastman Kodak, Rochester, Vt, USA, 4th edition, 2001.

[14] J. C. Domanus, Collimators for Thermal Neutron Radiography-An Overview, D. Reidel, Dordrecht, The Netherlands, 1987.

[15] M. R. Hawkesworth, "Neutron radiography: equipment and methods," Atomic Energy Review, vol. 15, no. 2, pp. 169-220, 1977.

[16] M. Holmes and D. J. Just, GRP in Structural Engineering, Applied Science Publishers, New York, NY, USA, 1983.

[17] J. G. Mohr and W. P. Rowe, Fiber Glass, Van Nostrand Reinhold, New York, NY, USA, 1978.

[18] Composites, Engineered Materials Handbook, vol. 21, ASM International, 1987.

[19] http://www.azom.com.

[20] http://www.enercon.de.

[21] http://www.vestas.com.

[22] K. Gibbs, H. Berger, T. Jones et al., "Flat panel imaging of thermal neutrons," in Proceedings of the ASNT Fall Conference, October 1999.

[23] C. Muralidhar, S. N. Lukose, and M. P. Subramanian, "Evaluation of turbine blades using computed tomography," in
Proceedings of the National Seminar on Non-Destructive Evaluation, Hyderabad, India, December 2006.

[24] T. P. Sattar, H. L. Rodriguez, and B. Bridge, "Climbing ring robot for inspection of offshore wind turbines," Industrial Robot, vol. 36, no. 4, pp. 326-330, 2009. 

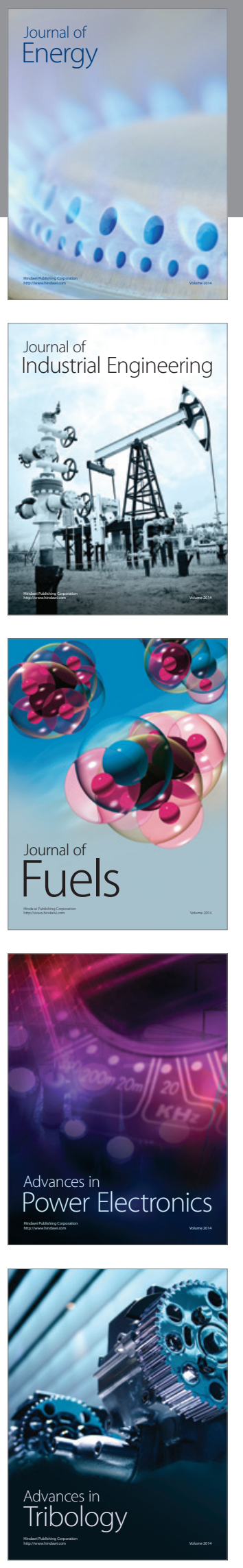
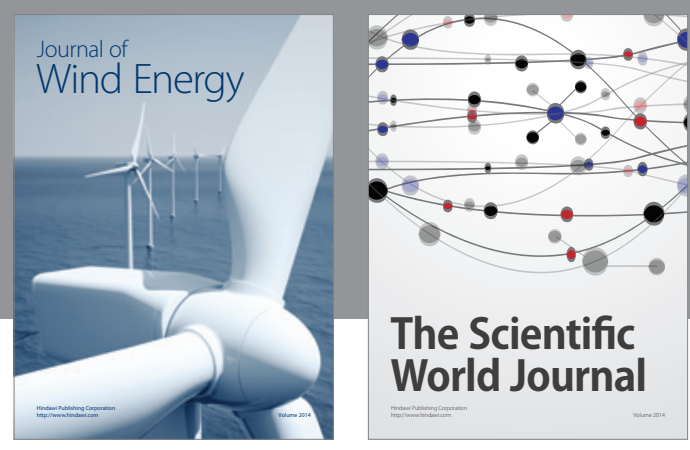

The Scientific World Journal

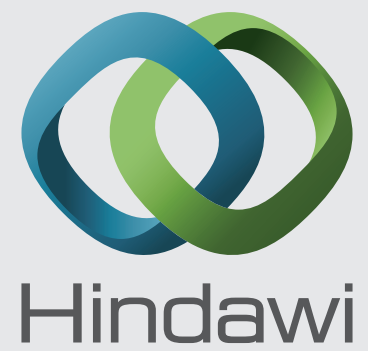

Submit your manuscripts at http://www.hindawi.com
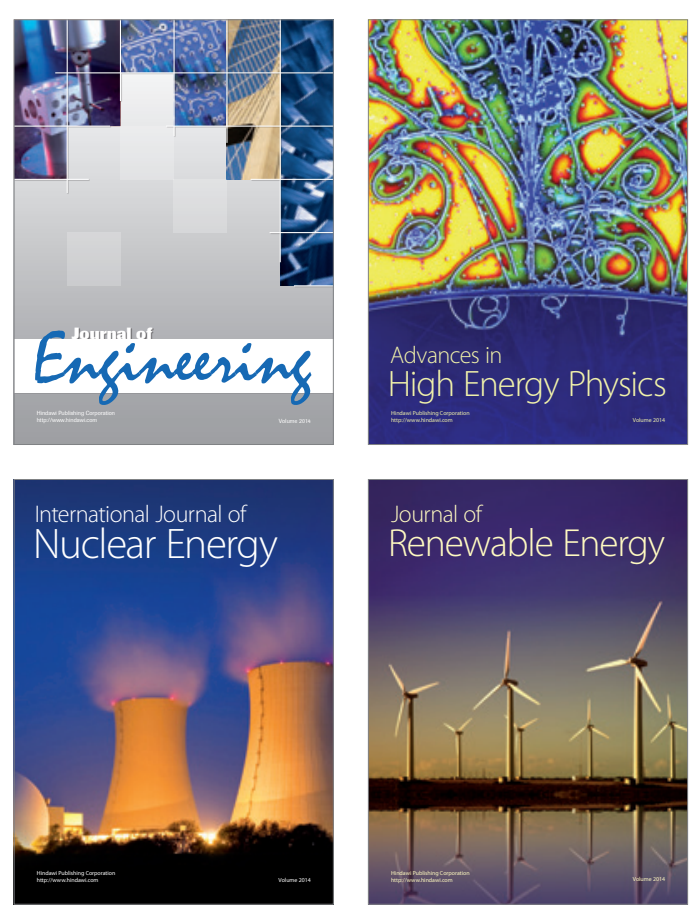

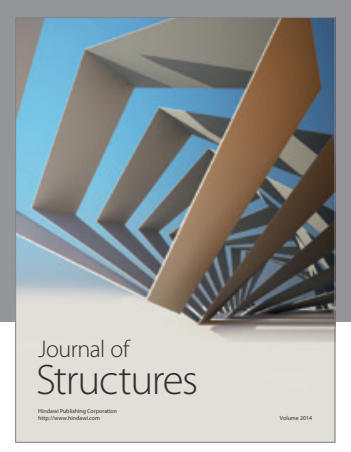

Rotating
Mechinery
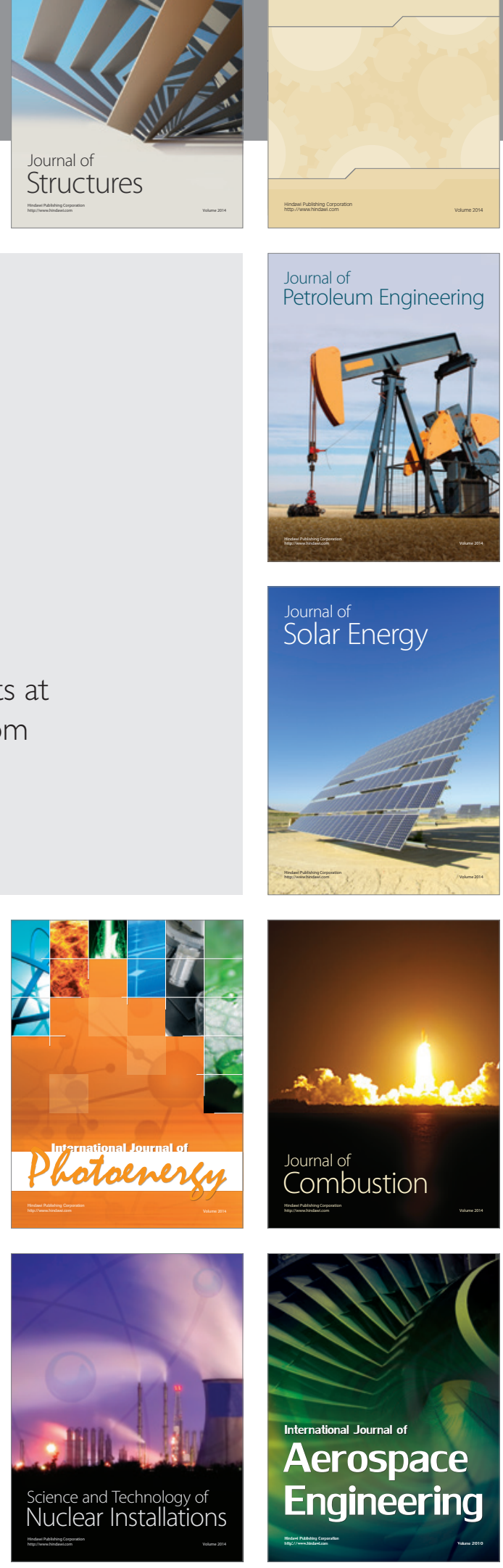